Original Article (short paper)

\title{
Is Football players' performance influenced by the quality of opposition? Application of the Golden Index formula in Club Atlético de Madrid 2016/2017
}

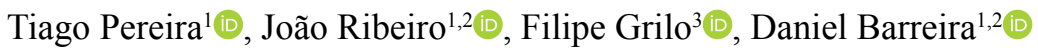 \\ ${ }^{1}$ Universidade do Porto, Faculty of Sport, Porto, Portugal; ${ }^{2}$ Universidade do Porto, Centre of Research, Training, Innovation \\ and Intervention in Sport, CIFI2D, Porto, Portugal; ${ }^{3}$ Universidade do Porto, Faculty of Economy, Porto, Portugal
}

\begin{abstract}
Aim: In this study, we sought to analyze the influence of the quality of opposition on players' performance of Club Atlético de Madrid (ATM) 2016/2017. For that, the Golden Index (GI) formula was applied to identify and rank the Golden Players of ATM when playing against opponents of different quality levels. Methods: GI formula variables were collected through notational analysis and three global adjacency matrices were constructed to record all successful ball-passing actions performed. Next, the matrices were imported to SocNetV to collect the network centrality metrics. To uniformize each variable, the statistical standardization technique was applied to all variables. ATM opponents were classified into three groups: high-level $(\mathrm{n}=4)$, medium-level $(\mathrm{n}=2)$ and low-level $(\mathrm{n}=2)$, according to their classification in La Liga and participation in the final stage of UEFA Champions League 2016/2017. Results: Koke was considered the Golden Player playing against high-level teams, while opposing low-level opponents he was ranked as second. Against medium- and low-level teams, Antoine Griezmann was considered the Golden Player, but was not classified in the three first positions against high-level opponents. Yannick Carrasco and Filipe Luís were ranked in the second and third positions, respectively, when playing against high- and medium-level opponents. Also, Saúl Ñíguez obtained the third higher index against low-level teams. Conclusions: This study evidenced that players' individual performance is influenced by the quality of the opposition. Additionally, the GI formula proved to be a potent tool in analyzing player's performance in attacking plays in Football.
\end{abstract}

Keywords: golden index formula, golden player, individual performance, quality of opposition.

\section{Introduction}

Quantifying the individual performance of football players within teams is always a challenging task due to the variability and complexity of game dynamics. Nevertheless, understanding the impact of the individual contribution of players to the overall team performance ${ }^{1}$, is paramount for aiding performance analysts and coaches to better optimize teams' training and selection, or even to enhance scouting methods ${ }^{2,3,4}$.

Notwithstanding the lack of literature regarding the abovementioned issues, researchers have already started to implement social network analysis to characterize the interactions displayed during competitive performance ${ }^{3,5}$. Network approach addresses the interdependencies underlying team structures, in which intra-group interactions are fundamental for the development and maintenance of collaborative behaviors, and includes aspects like cohesiveness, individual roles and hierarchies among players 5 . On the other hand, there exist a variety of network properties that can enlighten the structure and function of complex systems (e.g., player's individual performance within collectives), thus helping sport scientists, performance analysts and coaches, to better characterize the continuous interactions of teammates during competition. In this regard, for example, the degree centrality consists of the number of ties incident upon a node (i.e., a player) ${ }^{6}$. This network metric can be subdivided in Indegree (IC) and Outdegree centrality (OC) due to the directedness that characterize the ball-passing actions in football. The IC refers to the number of ties directed to a node (i.e., player), while $\mathrm{OC}$ measures the number of ties that a player directs to others ${ }^{6}$. Relating to football performance, both IC and OC provide information on the amount of passes that players receive and perform, respectively. These network metrics move beyond simplistic frequency counts of passes performed by players, providing information on how often players receive and pass the ball effectively ${ }^{5}$.

In spite of this, employment of traditional social network techniques presents some limitations that can effectively undermine its applicability ${ }^{7}$. Such limitations have been well identified in the works of Ribeiro, Silva, Duarte, Davids, Garganta $^{5}$ and Ramos, Lopes, Marques, Araújo ${ }^{8}$. One of such major limitations relates to the fact that network approach has been only focusing its analysis on ball-passing events, completely neglecting other important technical actions (e.g. dribble). That is why notational analysis have been applied in collaboration with the network analysis in football studies ${ }^{9}$, to help investigating the contribution of other essential technical and tactical aspects that may explain collective and individual performance $\mathrm{e}^{10,11}$. 
In this regard, several authors have created formulas $\mathrm{s}^{9,12,13}$ that allow measuring the real contribution of a player within a team, in successful attacking plays through analysis of other variables such as goals, dribbles, shots, etc ${ }^{9,12,13,14}$. According to those studies, a player is conditioned by his functions and/ or assigned roles within a team, being well-accepted that the individual actions developed by players during the game must contribute to an individual behavioral logic in which regards the stability and organization of the team, but also to create imbalance in the organization of the opposing team to increase team's success ${ }^{4}$. Kishore, Radhakrishnan and Karthick ${ }^{15}$ refer that the tactical-technical actions realized by footballers are influenced by the particularities of each tactical position, namely, the spatial-temporal references and specific assigned functions/roles ${ }^{16,17}$. However, given the unpredictability of the football game, Barreira ${ }^{18}$ refers that players also act and decide according to the information they perceive from the surrounding environments they are embedded. Hence, although there exists a generalized body of knowledge regarding which tacticaltechnical actions are required for each position, researches still fall short on scrutinizing this topic ${ }^{14,19}$. Thus, there is a need for more studies that may inform coaches about the real contribution of a player in attacking sub-phases of play in a non-standard way and considering situational variables as the quality of opposition ${ }^{10}$.

Indeed, the quality of opposition is extremely important to consider since during competition players interact in a symbiotic relationship of cooperation and opposition, exhibiting complex antagonist behaviors. On one hand, the team with ball-possession frequently tries to create space by stretching and expanding on field, aiming to create goalscoring opportunities. On the one hand, when defending, teams close down space by contracting and reducing space between players, aiming to recover ball-possession or to prevent the opposing team from creating scoring opportunities and scoring goals. Hence, situational variables like the quality of opposition have been regarded as an important influence factor on collective and individual performance $e^{10,11,20,21,22}$. Liu, Gómez, Gonçalves and Sampaio ${ }^{21}$, when analyzing the influence of the quality of opposition on players' behaviors, verified numerous variances between similar specific positions of top- and bottom- three teams. These authors concluded that the effects of the teams and opposition should be more carefully analyzed than other situational variables, such as match location, due to the high behavioral oscillation and influence of this variable on players' performance. Moreover, Taylor, Mellalieu, James, Sheraer ${ }^{10}$ highlighted that there are few studies that deepen the effects of the quality of opposition on collective and individual performance, due to a limited number of performance indicators.

Given the aforementioned, the objectives of this study are twofold: firstly, to apply the Golden Index (GI) formula ${ }^{23}$ to identify and classify the Golden Players (e.g. most important players in attacking plays) of Club Atlético de Madrid (ATM) in 2016/2017 season. Secondly, to analyze how players' individual performance is influenced by the quality of the opposition.

\section{Methods}

\section{Sample}

Eight ATM games played in 2016/2017 season were analyzed. All opponent teams were grouped into three levels ${ }^{13,24}$ :

a) high-level teams $(n=4)$ : teams playing in the final phase of Union of European Football Associations (UEFA) Champions League in 2016/2017 season and/ or classified from 1st to 3rd place in La Liga;

b) medium-level teams $(\mathrm{n}=2)$ : teams classified between $4^{\text {th }}$ and $13^{\text {th }}$ place in La Liga;

c) low-level teams $(n=2)$ : teams classified between $14^{\text {th }}$ and $20^{\text {th }}$ place in La Liga.

Table 1. Observed games of Club Atlético de Madrid in 2016/17 season

\begin{tabular}{lccc}
\hline \multicolumn{1}{c}{ Match } & Competition & Result & Opponent level \\
\hline $\begin{array}{l}\text { Leicester City Football } \\
\text { Club vs ATM }\end{array}$ & $\begin{array}{c}\text { Champions } \\
\text { League }\end{array}$ & $1-1$ & High \\
$\begin{array}{l}\text { ATM vs Real Madrid } \\
\text { Club de Fútbol } \\
\text { Real Madrid Cub de } \\
\text { League }\end{array}$ & $2-1$ & High \\
$\begin{array}{l}\text { Fútbol vs ATM } \\
\text { ATM vs Futbol Club } \\
\text { Barcelona }\end{array}$ & La Liga & $1-1$ & High \\
$\begin{array}{l}\text { ATM vs Sevilla Fútbol } \\
\text { Club }\end{array}$ & La Liga & $3-1$ & High \\
$\begin{array}{l}\text { Reial Club Deportiu } \\
\text { Espanyol de Barcelona } \\
\text { vs ATM }\end{array}$ & La Liga & $0-1$ & Medium \\
$\begin{array}{l}\text { Real Sporting de Gijón } \\
\text { vs ATM }\end{array}$ & La Liga & $1-4$ & Low \\
$\begin{array}{l}\text { ATM vs Unión Deportiva } \\
\text { Las Palmas }\end{array}$ & La Liga & $1-0$ & Low \\
\hline
\end{tabular}

Note: La Liga: Spanish league; ATM: Club Atlético de Madrid.

\section{Participants}

All Golden Index formula variables were observed for each ATM player, with the exception of the Goalkeepers, due to their reduced participation in the attacking plays, in particular in regards of the variables related to goal scoring, as well as their restricted positioning on the field ${ }^{9}$.

Table 2. Specific tactical positions of Club Atlético de Madrid in 2016/17 season players

\begin{tabular}{lccccr}
\hline \multicolumn{1}{c}{ Player } & SP & SCP & $\begin{array}{c}\text { Tp vs } \\
\text { H-L }\end{array}$ & $\begin{array}{c}\text { Tp vs } \\
\text { M-L }\end{array}$ & $\begin{array}{c}\text { Tp vs } \\
\text { L-L }\end{array}$ \\
\hline Ángel Correa & W & OM & 90 & - & 64 \\
Antoine Griezmann & SS & - & 371 & 186 & 184 \\
Diego Godín & CB & - & 371 & 186 & 94 \\
\hline
\end{tabular}

(To be continued) 
Table 2. Specific tactical positions of Club Atlético de Madrid in 2016/17 season players

\begin{tabular}{lccrrr}
\hline \multicolumn{1}{c}{ Player } & SP & SCP & $\begin{array}{c}\text { Tp vs } \\
\text { H-L }\end{array}$ & $\begin{array}{c}\text { Tp vs } \\
\text { M-L }\end{array}$ & $\begin{array}{c}\text { Tp vs } \\
\text { L-L }\end{array}$ \\
\hline Fernando Torres & S & - & 188 & 76 & 81 \\
Filipe Luís & FB & - & 355 & 186 & 94 \\
Gabi & CM & - & 371 & 186 & 188 \\
José Giménez & FB & CM & 155 & 92 & - \\
Juanfran & FB & - & 149 & 92 & - \\
Kevin Gameiro & S & - & 108 & 91 & 116 \\
Koke & WM & CM & 356 & 186 & 188 \\
Lucas Hernández & CB & FB & 39 & - & 188 \\
Nicolás Gaitán & W & - & - & 10 & 8 \\
Saúl Níguez & CM & WM & 339 & 186 & 126 \\
Sime Vrsaljko & FB & - & 94 & 2 & 188 \\
Stefan Savić & CB & - & 371 & 186 & 188 \\
Thomas Partey & CM & WM & 51 & 46 & 30 \\
Yannick Carrasco & W & - & 318 & 149 & 147 \\
\hline
\end{tabular}

Note: SP: Specific Position; SCP: Secondary Position; WM: Wide Midfielder; W: Winger; FB: Fullback; SS: Second Striker; CM: Centre Midfielder; S: Striker; CB: Centre-back; Tp: Time Played (min); H-L: High-level teams; M-L: Medium-level teams; L-L: Low-level teams.

\section{Procedures}

All conducted procedures followed a logic defined by the Golden Index formula ${ }^{23}$ to treat and standardize each variable for each player.

GOLDEN INDEX $=4.4615 *\left(\frac{\text { Assists }}{\text { Time played }}\right)+4.3077 *\left(\frac{\text { Goals }}{\text { Time played }}\right)$ $+4.0769 *\left(\frac{\text { Sucessful Dribbles }}{\text { Time played }}\right)+4.0769 *\left(\frac{\text { Positive Crosses }}{\text { Time played }}\right)+3.9231 *$ $\left(\frac{\text { Passes performed }}{\text { Time played }}\right)+3.8462 *\left(\frac{\text { Shots }}{\text { Time played }}\right)+3.7692 *\left(\frac{\text { Passes received }}{\text { Time played }}\right)+$ $3.6154 *\left(\frac{\text { Betweenness Centrality }}{\text { Time played }}\right)+3.5385 *\left(\frac{\text { Page Rank Prestige }}{\text { Time plaved }}\right)-3.4615 *$ $\left(\frac{\text { Ball Losses }}{\text { Time played }}\right)+3.4615 *\left(\frac{\text { IR: Closemess Centrality }}{\text { Time played }}\right)+3.2308 *\left(\frac{\text { Running with ball }}{\text { Time played }}\right)$

i) Ratio Variables

The following procedures were realized for each group of opponents:

Variables' quantities (see Pereira, Ribeiro, Grilo and Barreira) ${ }^{23}$ (passes performed, passes received, assists, ball losses, goals, positive crosses, running with ball, shots, and successful dribbles ( $1 \mathrm{x} 1)$ ), were divided by the time played per player, as well as the network variables (Betweenness Centrality; IRCC: Influence Range: Closeness Centrality; and Page Rank Prestige. Variables' definition are also available in Pereira, Ribeiro, Grilo and Barreira ${ }^{23}$.

For each attacking sequence, an adjacency matrix with all ATM players represented in an " $\mathrm{x}$ n " system ${ }^{25}$, was constructed. The sum of all matrices resulted in a global adjacency matrix representing the total interactions performed by players during the games. After that, the total number of passes performed and received, displayed in the adjacency matrices, were divided by the individual time played (for each player), multiplied by 1000 .

After this procedure, the three adjacency matrices (for each opponent's level - high, medium and low) were imported into Social Network Visualizer (SocNetV v2.3) software, to compute the values of the network metrics.

ii) Standardization of the variables:

The following steps were performed for each player in each of the twelve variables and for the three level of opponents. Excel was used for statistical treatment.

Table 3. Steps developed for the standardization of the Golden Index formula variables (adapted from Pereira, Barreira, Ribeiro, Grilo \& Barreira ${ }^{23}$ )

\begin{tabular}{|c|c|c|c|}
\hline Steps & Name & Description & Formula \\
\hline 1 & $\begin{array}{l}\text { Mean of each variable on the } \\
\text { team (X1) }\end{array}$ & $\begin{array}{l}\text { Values of each individual player, after being added up, } \\
\text { and divided by the number of players. }\end{array}$ & $\begin{array}{l}\qquad \mathrm{X} 1=\frac{\sum \mathrm{x}}{\mathrm{n}} \\
\sum \mathrm{x} \text { : sum of the values of each player } \\
\mathrm{n} \text { : number of players }\end{array}$ \\
\hline 2 & $\begin{array}{l}\text { Difference between the player's } \\
\text { ratio and the mean of the team in } \\
\text { each variable }(\mathrm{X} 2)\end{array}$ & $\begin{array}{l}\text { The player's individual value is measured by subtracting } \\
\text { his ratio value for the mean of the team in the variable } \\
\text { (1), obtaining negative or positive values, being below or } \\
\text { above the mean of the team in the variable }\end{array}$ & $\begin{array}{l}\qquad \mathrm{X} 2=\mathrm{Xo}-\mathrm{M} \\
\mathrm{Xo:} \text { player's ratio in the variable } \\
\text { M: mean of the variable }\end{array}$ \\
\hline 3 & $\begin{array}{l}\text { Standard deviation of the values } \\
\text { of all team players for each } \\
\text { variable (S) }\end{array}$ & $\begin{array}{l}\text { The determination of the standard deviation }(\mathrm{S}) \text { of } \\
\text { the variable allows verifying to verify the measure of } \\
\text { dispersion relatedive to the means. This can only assume } \\
\text { non-negative values, and the greater its value, the greater } \\
\text { is the dispersion of the sample. }\end{array}$ & $\begin{array}{l}\qquad S=\sqrt{\frac{\sum(x i-x)^{2}}{n-1}} \\
\text { Xi: value at position } i \text { in the data } \\
X \text { : mean of the data } \\
\text { n-1: amount of data minus } 1\end{array}$ \\
\hline 4 & $\begin{array}{l}\text { Standardization of each variable } \\
(Z)\end{array}$ & $\begin{array}{l}\text { The value of the player (2) is subtracted by the mean } \\
\text { value of all players for each variable (1), divided by the } \\
\text { standard deviation of all players for each variable ( } 3 \text { ). }\end{array}$ & $\begin{array}{l}\qquad Z=\frac{x-\mu}{\sigma} \\
x: \text { value of the player (2) } \\
\mu \text { : mean of all players in the variable (3) } \\
\sigma: \text { standard deviation of the players in } \\
\text { the variable (4) }\end{array}$ \\
\hline
\end{tabular}




\section{Results}

This study shows the application of the GI formula to ATM $2016 / 17$, when playing against opponents of different quality levels, namely high-, medium- and low-level opponents.

\section{High-level teams}

The results of the GI formula application to ATM while playing against high-level opponents indicated Koke (GI: 39,846), Yannick Carrasco (GI: 35,863) and Filipe Luís (GI: 27,565) as the Golden Players. Koke (wide midfielder) was considered the Golden Player since he obtained the highest values of the team in the passes received (PRec: 0,404) and passes performed (PPer: 0,430) variables. In addition, he obtained high values in the variables page rank prestige (PR: 0,086), betweenness centrality (BC: 341.9), influence range: closeness centrality (IRCC: 30.3 ), positive crosses (PCr: 0,006) and assists (A: 0,022). Ranked in the second position performed Yannick Carrasco (winger), with the highest value of the team in the variable running with the ball (RB: $0,041)$. This player also obtained high values in shots (Shots: 0,016), assists (A: 0,016) and successful dribbles (1x1) (DB: $0,016)$ variables. Filipe Luís (fullback) was classified in the third place, performing the highest indexes of ATM in the variables betweenness centrality (BC: 487.5) and positive crosses (PCr: 0,008).

Table 4. Club Atlético de Madrid 2016/17 players' ranking in the matches with high-level opponents using the Golden Index formula

\begin{tabular}{|c|c|c|c|c|c|c|c|c|c|c|c|c|c|c|c|}
\hline $\mathbf{R}$ & Player & SP & GI & PRec & PPer & PR & BC & IRCC & $\mathbf{P C r}$ & RB & $* \mathbf{B L}$ & DB & $\mathbf{A}$ & Shots & Goal \\
\hline 1 & Koke & WM & 39.846 & 0.404 & 0.430 & 0.086 & 341.9 & 30.3 & 0.006 & 0.008 & 0.169 & 0.003 & 0.022 & 0.003 & 0 \\
\hline 2 & Yannick Carrasco & W & 35.863 & 0.299 & 0.208 & 0.069 & 0 & 24.6 & 0.003 & 0.041 & 0.145 & 0.016 & 0.016 & 0.016 & 0 \\
\hline 3 & Filipe Luís & FB & 27.565 & 0.279 & 0.287 & 0.069 & 487.5 & 27.6 & 0.008 & 0.017 & 0.124 & 0.003 & 0.003 & 0.003 & 0 \\
\hline 4 & Gabi & $\mathrm{CM}$ & 20.467 & 0.358 & 0.420 & 0.114 & 188.3 & 30.7 & 0 & 0.005 & 0.178 & 0.003 & 0.011 & 0.003 & 0 \\
\hline 5 & Antoine Griezmann & SS & 16.425 & 0.253 & 0.218 & 0.085 & 1.5 & 26.2 & 0 & 0.022 & 0.146 & 0 & 0.003 & 0.016 & 0.005 \\
\hline 6 & Saúl Ñ́guez & $\mathrm{CM}$ & 13.634 & 0.206 & 0.183 & 0.080 & 0 & 24.4 & 0 & 0.006 & 0.094 & 0.003 & 0 & 0.018 & 0.006 \\
\hline 7 & Kevin Gameiro & $\mathrm{S}$ & 3.950 & 0.148 & 0.083 & 0.040 & 0 & 14.7 & 0 & 0.019 & 0.037 & 0.009 & 0.009 & 0.019 & 0 \\
\hline 8 & Ángel Correa & W & -4.564 & 0.211 & 0.156 & 0.045 & 0 & 12.1 & 0 & 0.022 & 0.078 & 0 & 0.011 & 0.011 & 0 \\
\hline 9 & Diego Godín & $\mathrm{CB}$ & -10.367 & 0.124 & 0.124 & 0.047 & 0 & 22.4 & 0 & 0 & 0.040 & 0 & 0 & 0.008 & 0.003 \\
\hline 10 & Fernando Torres & $\mathrm{S}$ & -11.849 & 0.128 & 0.043 & 0.067 & 0 & 9.4 & 0 & 0.011 & 0.074 & 0.005 & 0 & 0.016 & 0 \\
\hline 11 & Juanfran & FB & -15.783 & 0.235 & 0.262 & 0.054 & 0 & 20.8 & 0 & 0.007 & 0.141 & 0 & 0 & 0 & 0 \\
\hline 12 & Stefan Savić & $\mathrm{CB}$ & -17.126 & 0.065 & 0.116 & 0.056 & 0 & 23.1 & 0 & 0 & 0.022 & 0 & 0 & 0.005 & 0 \\
\hline 13 & José Giménez & FB & -19.845 & 0.135 & 0.200 & 0.062 & 0 & 19.8 & 0 & 0 & 0.194 & 0.006 & 0 & 0 & 0 \\
\hline 14 & Thomas Partey & $\mathrm{CM}$ & -20.546 & 0.157 & 0.196 & 0.034 & 0 & 9.2 & 0 & 0.020 & 0.059 & 0 & 0 & 0 & 0 \\
\hline 15 & Šime Vrsaljko & FB & -26.460 & 0 & 0.117 & 0.029 & 12.560 & 0 & 0 & 0.053 & 0 & 0.011 & 0 & 0 & 0 \\
\hline 16 & Lucas Hernández & $\mathrm{CB}$ & -31.210 & 0.128 & 0.051 & 0.034 & 0 & 10.0 & 0 & 0 & 0.051 & 0 & 0 & 0 & 0 \\
\hline 17 & Nicolás Gaitán & W & - & - & - & - & - & - & - & - & - & - & - & - & - \\
\hline
\end{tabular}

Note: R. Ranking; P: Position; WM: Wide Midfielder; W: Winger; FB: Fullback; SS: Second Striker; CM: Centre Midfielder; S: Striker; CB: Centreback; GI: Golden Index; PRec: Passes Received; PPer: Passes Performed; PR: Page Rank Prestige; BC: Betweenness Centrality; IRCC: Influence Range: Closeness Centrality; PCr: Positive Crosses; *BL: Ball losses (this value appears with a negative connotation, thus, the higher the value, the final index gets inferior); RB: Running with the Ball; DB: Successful Dribbles (1x1); A: Assists; Goal: Goals.

\section{Medium-level teams}

GI formula application to ATM playing against mediumlevel opponents ranked Antoine Griezmann (GI: 32,560), Yannick Carrasco (GI: 25,287) and Filipe Luís (GI: 17,861) as the Golden Players. Antoine Griezmann, playing as second striker, obtained the highest index of the team in goals (Goal: 0,011) and running with the ball (RB: 0,075) variables. Moreover, he obtained high index in variables shots (Shots: 0,022), assists (A: 0,011) and page rank prestige (PR: 0.108). Therefore, Griezmann displayed a greater participation in the ball-passing network of ATM 2016/2017 when playing against medium-level opponents.

Yannick Carrasco (winger) and Filipe Luís (fullback), similarly to high-level opponents, were ranked in the second and third positions, respectively, however, with a decrease in their index. Particularly, Carrasco obtained the highest index of the team in the variables shots (Shots: 0,027), successful dribbles (1x1) (DB: 0,020) and page rank prestige (PR: 0.116), while Filipe Luís also obtained high index in betweenness centrality (BC: 369.9$)$ and influence range: closeness centrality (IRCC: 18.5) metrics, and in positive crosses ( $\mathrm{PCr}: 0,005)$. 
Table 5. Club Atlético de Madrid 2016/17 players' ranking in the matches with medium-level opponents using the Golden Index formula

\begin{tabular}{|c|c|c|c|c|c|c|c|c|c|c|c|c|c|c|c|}
\hline $\mathbf{R}$ & Player & SP & GI & PRec & PPer & PR & BC & IRCC & PCr & RB & ${ }^{*} \mathbf{B L}$ & DB & $\mathbf{A}$ & Shots & Goal \\
\hline 1 & Antoine Griezmann & SS & 32.560 & 0.395 & 0.333 & 0.108 & 10.0 & 17.5 & 0 & 0.075 & 0.075 & 0 & 0.011 & 0.022 & 0.011 \\
\hline 2 & Yannick Carrasco & $\mathrm{W}$ & 25.287 & 0.369 & 0.268 & 0.116 & 4.250 & 16.7 & 0 & 0.040 & 0.121 & 0.020 & 0.013 & 0.027 & 0 \\
\hline 3 & Filipe Luis & FB & 17.861 & 0.333 & 0.387 & 0.079 & 369.0 & 18.5 & 0.005 & 0.022 & 0.070 & 0.005 & 0.005 & 0.011 & 0 \\
\hline 4 & Koke & WM & 16.437 & 0.435 & 0.398 & 0.092 & 131.5 & 18.2 & 0 & 0.016 & 0.081 & 0.005 & 0.011 & 0.005 & 0.005 \\
\hline 5 & Nicolás Gaitán & $\mathrm{W}$ & 8.530 & 0.400 & 0.400 & 0.021 & 0 & 19.3 & 0 & 0 & 0 & 0 & 0.100 & 0 & 0 \\
\hline 6 & Diego Godín & $\mathrm{CB}$ & 6.127 & 0.194 & 0.247 & 0.060 & 891.8 & 17.1 & 0 & 0.005 & 0.054 & 0 & 0 & 0.005 & 0.005 \\
\hline 7 & Gabi & $\mathrm{CM}$ & 3.826 & 0.333 & 0.435 & 0.072 & 56.0 & 19.5 & 0 & 0.016 & 0.043 & 0.005 & 0 & 0 & 0 \\
\hline 8 & Saúl Ñíguez & $\mathrm{CM}$ & -2.169 & 0.280 & 0.296 & 0.075 & 33.5 & 17.1 & 0 & 0.011 & 0.032 & 0 & 0.005 & 0.016 & 0 \\
\hline 9 & Fernando Torres & S & -3.956 & 0.211 & 0.132 & 0.055 & 0 & 14.0 & 0.013 & 0.013 & 0.053 & 0 & 0 & 0.013 & 0 \\
\hline 10 & Šime Vrsaljko & $\mathrm{FB}$ & -9.562 & 1 & 0.5 & 0.025 & 0 & 19.2 & 0 & 0 & 0.5 & 0 & 0 & 0 & 0 \\
\hline 11 & Juanfran & FB & -9.837 & 0.185 & 0.228 & 0.044 & 0 & 15.9 & 0 & 0 & 0.043 & 0.011 & 0 & 0.011 & 0 \\
\hline 12 & Thomas Partey & $\mathrm{CM}$ & -12.542 & 0.239 & 0.283 & 0.053 & 0 & 17.3 & 0 & 0.022 & 0.043 & 0 & 0 & 0 & 0 \\
\hline 13 & Kevin Gameiro & S & -17.418 & 0.231 & 0.077 & 0.067 & 0 & 12.4 & 0 & 0.011 & 0.099 & 0 & 0.011 & 0.022 & 0 \\
\hline 14 & José Giménez & $\mathrm{FB}$ & -27.214 & 0.174 & 0.174 & 0.051 & 0 & 14.3 & 0 & 0 & 0.098 & 0 & 0 & 0 & 0 \\
\hline 15 & Stefan Savić & $\mathrm{CB}$ & -27.931 & 0.124 & 0.145 & 0.052 & 0 & 13.6 & 0 & 0 & 0.032 & 0 & 0 & 0 & 0 \\
\hline 16 & Ángel Correa & $\mathrm{W}$ & - & - & - & - & - & - & - & - & - & - & - & - & - \\
\hline 17 & Lucas Hernández & $\mathrm{CB}$ & - & - & - & - & - & - & - & - & - & - & - & - & - \\
\hline
\end{tabular}

Note: R. Ranking; P: Position; WM: Wide Midfielder; W: Winger; FB: Fullback; SS: Second Striker; CM: Centre Midfielder; S: Striker; CB: Centreback; GI: Golden Index; PRec: Passes Received; PPer: Passes Performed; PR: Page Rank Prestige; BC: Betweenness Centrality; IRCC: Influence Range: Closeness Centrality; PCr: Positive Crosses; ${ }^{*} \mathrm{BL}$ : Ball losses (this value appears with a negative connotation, thus, the higher the value, the final index gets inferior); RB: Running with the Ball; DB: Successful Dribbles (1x1); A: Assists; Goal: Goals.

\section{Low-level teams}

Results found in ATM matches against low-level opponents highlighted, once again, Antoine Griezmann (GI: 30,016) as the Golden Player, followed by Koke (GI: 29,754) and Saúl Ñíguez (GI: 19,601) in second and third positions, respectively.

Antoine Griezmann (second striker) presented the highest values of the team in the following variables: page rank prestige (PR: 0.086) and running with the ball (RB: 0,027). This player also achieved high values in successful dribbles (DB:
0,011), assists (A: 0,016) and shots $(0,022)$ variables. Koke showed a performance that ranked him as the second place Golden Player, displaying the highest values of the team in the variables passes received (PRec: 0,431), passes performed (PPer: 0,394), betweenness centrality (BC: 253.6) and influence range: closeness centrality (IRCC: 19.0 ). In the third position appear Saúl Ñiguez (preferably a centre midfielder) as one of the Golden Players, exhibiting high values in the following variables: shots (Shots: 0,024), goal (Goal: 0,008) and page rank prestige (PR: 0,081).

Table 6. Club Atlético de Madrid 2016/17 players' ranking in the matches with low-level opponents using the Golden Index formula

\begin{tabular}{|c|c|c|c|c|c|c|c|c|c|c|c|c|c|c|c|}
\hline $\mathbf{R}$ & Player & SP & GI & PRec & PPer & PR & BC & IRCC & PCr & RB & ${ }^{*} \mathbf{B L}$ & DB & $\mathbf{A}$ & Shots & Goal \\
\hline 1 & Antoine Griezmann & SS & 30.016 & 0.245 & 0.174 & 0.086 & 46.5 & 14.8 & 0 & 0.027 & 0.076 & 0.011 & 0.016 & 0.022 & 0 \\
\hline 2 & Koke & WM & 29.754 & 0.431 & 0.394 & 0.079 & 253.6 & 19.0 & 0 & 0.005 & 0.069 & 0 & 0.011 & 0.011 & 0 \\
\hline 3 & Saúl Ñíguez & $\mathrm{CM}$ & 19.601 & 0.310 & 0.294 & 0.081 & 30.5 & 16.8 & 0 & 0.024 & 0.063 & 0 & 0 & 0.024 & 0.008 \\
\hline 4 & Yannick Carrasco & $\mathrm{W}$ & 17.601 & 0.224 & 0.150 & 0.069 & 15.0 & 12.4 & 0.007 & 0.027 & 0.061 & 0 & 0.007 & 0.014 & 0.007 \\
\hline 5 & Šime Vrsaljko & $\mathrm{FB}$ & 15.055 & 0.191 & 0.250 & 0.073 & 0 & 16.3 & 0.005 & 0.021 & 0.069 & 0.005 & 0.005 & 0.005 & 0 \\
\hline 6 & Gabi & $\mathrm{CM}$ & 10.143 & 0.303 & 0.356 & 0.078 & 67.9 & 17.7 & 0 & 0.005 & 0.059 & 0 & 0.011 & 0.005 & 0 \\
\hline 7 & Kevin Gameiro & S & 7.926 & 0.198 & 0.121 & 0.065 & 0 & 13.0 & 0 & 0.017 & 0.069 & 0 & 0 & 0.017 & 0.026 \\
\hline 8 & Thomas Partey & $\mathrm{CM}$ & 6.824 & 0.267 & 0.333 & 0.037 & 0 & 18.9 & 0 & 0 & 0.033 & 0 & 0.033 & 0 & 0 \\
\hline 9 & Filipe Luis & $\mathrm{FB}$ & 0.038 & 0.351 & 0.394 & 0.051 & 16.0 & 19.6 & 0 & 0.011 & 0.074 & 0 & 0 & 0 & 0 \\
\hline 10 & Lucas Hernández & $\mathrm{CB}$ & -7.929 & 0.186 & 0.250 & 0.055 & 7.3 & 17.3 & 0 & 0.011 & 0.016 & 0 & 0 & 0 & 0 \\
\hline 11 & Fernando Torres & $\mathrm{S}$ & -10.824 & 0.259 & 0.111 & 0.067 & 0 & 11.3 & 0 & 0.012 & 0.136 & 0 & 0.012 & 0.012 & 0 \\
\hline 12 & Stefan Savić & $\mathrm{CB}$ & -16.228 & 0.144 & 0.202 & 0.067 & 23.7 & 13.8 & 0 & 0 & 0.037 & 0 & 0 & 0 & 0 \\
\hline 13 & Diego Godín & $\mathrm{CB}$ & -22.809 & 0.106 & 0.117 & 0.035 & 0 & 11.4 & 0 & 0 & 0.021 & 0 & 0 & 0.011 & 0 \\
\hline
\end{tabular}


Table 6. Club Atlético de Madrid 2016/17 players' ranking in the matches with low-level opponents using the Golden Index formula

\begin{tabular}{|c|c|c|c|c|c|c|c|c|c|c|c|c|c|c|c|}
\hline $\mathbf{R}$ & Player & SP & GI & PRec & PPer & PR & BC & IRCC & PCr & RB & $* \mathrm{BL}$ & DB & $\mathbf{A}$ & Shots & Goal \\
\hline 14 & Ángel Correa & $\mathrm{W}$ & -27.662 & 0.188 & 0.125 & 0.038 & 0 & 13.6 & 0 & 0.016 & 0.141 & 0 & 0 & 0 & 0 \\
\hline 15 & Nicolás Gaitán & $\mathrm{W}$ & -51.884 & 0.125 & 0 & 0.014 & 0 & 0 & 0 & 0 & 0.125 & 0 & 0 & 0 & 0 \\
\hline 16 & José Giménez & FB & - & - & - & - & - & - & - & - & - & - & - & - & - \\
\hline 17 & Juanfran & FB & - & - & - & - & - & - & - & - & - & - & - & - & - \\
\hline
\end{tabular}

Note: R. Ranking; P: Position; WM: Wide Midfielder; W: Winger; FB: Fullback; SS: Second Striker; CM: Centre Midfielder; S: Striker; CB: Centreback; GI: Golden Index; PRec: Passes Received; PPer: Passes Performed; PR: Page Rank Prestige; BC: Betweenness Centrality; IRCC: Influence Range: Closeness Centrality; PCr: Positive Crosses; *BL: Ball losses (this value appears with a negative connotation, thus, the higher the value, the final index gets inferior); RB: Running with the Ball; DB: Successful Dribbles (1x1); A: Assists; Goal: Goals.

\section{Discussion}

The GI formula application to ATM 2016/17 allows to understand the individual contribution of the players in the attacking plays, as demonstrated in a recent study ${ }^{23}$. Previous literature has not been able to demonstrate, using several performance indicators, how players' performance can be influenced objectively through contextual factors, such as the quality of opposition, and not only by structure factors (e.g. tactical principles of play and/or strategical game plan ${ }^{26}$ ).

In this study, we propose to objectify how the individual performance in football can be conditioned by the quality of opposition, identifying the attacking references of Club Atlético de Madrid (ATM) in 2016/17 season.

\section{High-level teams}

Results from our data indicated that players who played, preferably, through the lateral paths of the field were nominated Golden Players of ATM when competing against high-level opponents. In specific, Koke (wide midfielder), Yannick Carrasco (winger) and Filipe Luís (fullback) were considered the Golden Players of ATM against Futbol Club Barcelona (FCB) and Real Madrid Club de Fútbol (RM), considering La Liga competition, and RM and Leicester City Football Club (LCFC) in UEFA Champions League, in 2016/2017 season.

Koke (wide midfielder) was considered the most important player against the four high-level teams, assuming a key role in the ball-passing network (PRec, PPer, PR, BC and IRCC, see Table 4). Grund ${ }^{27}$ claimed that high values of centrality might indicate a great dependence of a team on the activity of a given player. $\mathrm{Zhu}^{28}$ refers that high centrality values (e.g. IRCC and $\mathrm{BC}$ ) indicate the well-connectedness (i.e. performs and receives more passes) of a given player within a team. Such evidences confirm that Koke possibly has played a fundamental role in the orchestration and organization of ATM attacking patterns of play, acting as an intermediary in connecting more often other pairs of players, due to his levels of betweenness centrality ${ }^{29,30}$. Additionally, Koke was considered the second player with more assists and positive crosses per time played. These behaviors have similarities to ball-passing metrics, but occur in more attacking zones of the field. This suggests that Koke played an important role in the pre-finalization and creation sub-phases of play ${ }^{31}$, that is, he appeared more often in advanced zones of the field, contributing to team's attacking success using diverse types of passes.

Yannick Carrasco (winger) was considered the second Golden Player of ATM against high-level opponents, which is proved by his high values in the variables of successful dribbles $(1 \mathrm{x} 1)$, running with the ball and shots. In general, he played in the lateral paths of the pitch, presenting high levels of freedom in both on-the-ball and off-the-ball movements, performing individual actions in order to break the opponent's defensive organization and to play in scoring zones ${ }^{26}$. The works of Wiemeyer ${ }^{32}$ and Cullinane $^{33}$ corroborate such results, since authors suggested that wingers should present good dribbling skills, with freedom to perform individual actions and duels in advanced zones of the pitch. Thus, when competing with high-level opponents, ATM possibly defined as strategical game plan the use of faster attacks and/or counter-attacks, with Carrasco evidencing a major role on this playing offensive method. In resume, Koke and Carrasco were considered the most ranked players against strong opponents but showing high performances in different variables included in the GI formula. The first using a more collective play through passing behaviors, and the second mostly applying individual behaviors. So, both players were considered the most important players in attacking sub-phases of play in ATM, but completing different roles.

Filipe Luís (fullback) was ranked in third position showing the highest values of the team in the variables betweenness centrality and positive crosses, evidencing high participation in ATM passing network. Castelo ${ }^{4}$ and Marques ${ }^{34}$ underlined the importance of fullbacks in team's attacking process to unbalance the opponent's defensive organization, by performing off-theball movements and promoting numerical superiority along the lateral path. Filipe Luís showed high preponderance in the ATM attacking plays, performing the greatest number of positive crosses achieved. Our results corroborate Gonçalves, Coutinho, Santos, Lago-Peñas, Jiménez and Sampaio ${ }^{35}$ study since high centrality values (e.g. BC) might indicate that Filipe Luís is a highly connected player in ATM passing network, functioning as an intermediary and/or bridge connecting other players from different sectors of play. Similar findings were observed by $\mathrm{Jaria}^{36}$ when the author found that players who occupied the left defensive position presented high interactions on the team. Moreover, Barghi ${ }^{29}$ studying the Spanish National team in the World Cup 2010, found that left fullback Joan Capdevilla was one 
of the players with highest values on the variable betweenness centrality, adding that remove well rated players in $\mathrm{BC}$ variable may condition teams' ball-flow ${ }^{30}$.

\section{Medium-level teams}

The results of the GI formula application to ATM against medium-level opponents - Sevilla Fútbol Club and Reial Club Deportiu Espanyol de Barcelona - suggested Antoine Griezmann (second striker) as the Golden Player of the team. Yannick Carrasco (winger) and Filipe Luís (fullback) remained as the other Golden Players.

Contrarily to Koke (found as first Golden Player against high-level opponents), Antoine Griezmann obtained the highest values of the team in the variables goals and running with the ball. He also obtained high values in shots, assists and page rank prestige variables. This data may suggest that Griezmann and Koke have different assigned functions and/or roles in ATM. Griezmann is undoubtedly a target player, a major reference in the creation of goal-scoring opportunities, verified by his high values presented in the variables shots and goals ${ }^{31}$.

Beyond that, contrarily to the values presented by Griezmann against high-level opponents, opposing medium-level teams he exhibited a major participation on teams' attacking patterns of play, probably due to less efficient individual marking impinged by the opponent players, but also due to greater support and passing lines offered by his teammates ${ }^{5}$. This is indicated by the values of page rank prestige, betweenness centrality and influence range: closeness centrality variables, signifying that he had high probability in receiving and passing the ball ${ }^{29,30}$.

In second and third position, appeared once again Yannick Carrasco and Filipe Luís as the Golden Players. These data might indicate that, regardless of the opponent level, these players, both playing preferentially in the lateral corridors of the pitch, assumed themselves as references in the construction and creation phases ${ }^{31}$ of ATM attacking plays. Therefore, we agree with Belli's ${ }^{37}$ when the author stressed that quantifying players' performance may also reveal standards in the team's collective game.

\section{Low-level teams}

The results of the GI formula application to ATM against lowlevel opponents (Real Sporting de Gijón and Unión Deportiva Las Palmas) highlighted Antoine Griezmann (second striker), Koke (wide midfielder) and Saúl Níguez (centre midfielder) as the Golden Players of ATM in the attacking sub-phases of play.

Antoine Griezmann tended to receive more frequently the ball, verified by his high values on the variable page rank prestige, and have developed his individual actions mainly through running with the ball actions. Similar to medium-level opponents, Griezmann displayed a major participation on teams' attacking plays probably due to the employment of less individual marking by the opposing team and/or the development of higher dynamics with and without the ball. This player achieved high values in the variables successful dribbles (1x1), assists and shots, thus corroborating the hypothesis of being a fundamental player in the development of successful attacking plays of ATM, appearing in scoring zones, as evidenced in the games against medium-level opponents.

Once again, Koke was considered one of the Golden Players against low-level opponents, obtaining the highest values of the team in the centrality variables: passes performed, passes received and betweenness centrality. This data might indicate that Koke had a preponderant role in the offensive organization of the team, providing high support and cover to teammates, also acting as a pivot to connect other players in different game sectors. Saúl Ñ́guez (preferably a centre midfielder) achieved the third highest index of the team. This player presented high values in shots, goals and page rank prestige variables, indicating a high tendency to appear in scoring zones ${ }^{31}$ and for receiving more passes. In fact, research ${ }^{12,38,39,40}$ provided evidence that centre midfielders present a significant role in the organization of the team interactions, beyond maintaining the collective attacking and defensive balance ${ }^{39}$. Liu, Gómez, Gonçalves and Sampaio $^{24}$, analyzing three top- and three bottom-teams from La Liga 2012-2013, found that the centre midfielders of the top teams, contrarily to ones of the bottom teams, obtained a high number of passes received and performed. Beyond that, one of the main functions of centre midfielders was to organize the attacking process by masterful ball controls and passes, instead of invading the opponent's area ${ }^{24,32}$, through ball conduction movements. However, these authors ${ }^{24}$ also verified that centre midfielders of bottom-teams performed more shots in comparison with the centre midfielders of top-teams. Therefore, given such results, we suggest that Saúl Níguez went beyond what is regular normal for a centre midfielder to perform in the attacking process ${ }^{26}$, obtaining high levels of offensive participation probably due to a context of less defensive exerted by the opponents.

Furthermore, we have also noticed some sort of positional variation of Saúl Ñíguez during performance by sometimes occupying wide midfielder positions, which may be indicative of some versatility employed in the attacking plays of ATM. Similar to other two conditions (high-level and medium-level opponents), Saúl performed a high number of shots which could indicate that beyond the structural disposition of players on field, the functionality (e.g., movements, decision-making, technical-tactical actions) evidenced by players within and between tactical positions is extremely important to consider. Here, players' characteristics, the quality of the opposition and the coaches' game model (e.g., tactical principles of play and/ or strategical game plan $)^{26}$ and group tactics (e.g. cooperation between sub groups within a team)11 can strongly impact on such functionality.

\section{Conclusion}

This paper aimed to analyze the influence of the situational variable quality of the opposition in players' individual performance over the competition. For that, we have applied the GI formula to identify and rank the Golden Players of Club Atlético de 
Madrid (ATM) in 2016/2017 season, considering the opponents' competitive level, namely: high-, medium- and low-level.

The GI formula application to ATM attacking plays revealed some interesting results. Firstly, Koke and Antoine Griezmann were identified as the Golden Players of the team, which curiously is in line with the opinion of most football specialists. Secondly, and more importantly, the players indexes of performance (GI values) varied according to the quality of the opposition and the characteristics of ATM attacking plays. This means that the GI formula may also be sensible in capturing the influence of other situational variables and/or constraints (e.g., match venue) in identifying the emergence of different prominent players within teams during attacking sub-phases of play.

Thus, our data suggests that the individual actions performed by players during attacking plays appear to be conditioned by their assigned positional roles and/or functions within the teams' game system, and, of course, the quality of the opposition. Notwithstanding, for a fair and realistic analysis of the real contribution of a player for the overall team performance, efforts shall be made to understand each player as a complex adaptive system whose functionality is influenced by several performance constraints such as the quality of the opposition and the positional status. To conclude, the applicability of the GI formula comprises a potent instrument to identify and classify players' individual performances in team games like football, hence aiding coaches and performance analysts in better understanding the real contribution of players for the overall team performance and success in attacking sub-phases of play.

\section{Limitations and Future Research}

The applicability of the GI formula is limited only to the study of the attacking plays. Hence, in future studies, other variables associated to attacking but also defending sub-phases of play should be inserted in this formula so that it could extend even more its impact on the analysis of players' individual performances within teams, thus providing coaches and performance analysts with more detailed information regarding the impact of a given player in the overall team performance. In addition, the applicability of the GI formula in other contexts involving other teams (e.g., elite vs non-elite) and players (e.g., youth teams), and considering the influence of other interactional situational variables (match venue*quality of opposition*game result), can provide novel and useful insights regarding how players behave under distinct conditions of competitive performance. Also, incorporating other information, such as Voronoi-diagrams ${ }^{11,41}$ or GPS information ${ }^{42}$, can help coaches and performance analysts to have a deeper analysis of players' spatial and temporal control with and without the ball during the football game.

\section{References}

1. Maneiro R, Amatria M. Polar Coordinate Analysis of Relationships With Teammates, Areas of the Pitch, and Dynamic Play in Soccer: A Study of Xabi Alonso. Front Psychol. 2018; 9:389 [ Link ]
2. Robertson S, Gupta R, McIntosh S. A method to assess the influence of individual player performance distribution on match outcome in team sports. J Sports Sci Med. 2016; 34 (19): 18931900 [ Link ]

3. Malta P, Travassos B. Caracterização da transição defesa-ataque de uma equipa de futebol. Motricidade. 2014; 10(1): 27-37 [ Link ]

4. Castelo J. Futebol - A organização do jogo. Edição do autor. Lisboa, 1996.

5. Ribeiro J, Silva P, Duarte R, Davids K, Garganta J. Team Sports Performance Analysed Through the Lens of Social Network Theory: Implications for Research and Practice. Sports Med. 2017; 47: 1689-1696 [ Link ]

6. Borgatti SP. Centrality and network flow. Soc Netw. 2005; 27:55-71 [Link]

7. Lusher D, Robins G, Kremer P. The application of social network analysis to team sports. Meas Phys Educ Exerc Sci. 2010; 14:211-24 [Link]

8. Ramos J, Lopes RJ, Marques P, Araújo D. Hypernetworks Reveal Compound Variables That Capture Cooperative and Competitive Interactions in a Soccer Match. Front Psychol. 2017; 8:1379 [Link]

9. Duch J, Waitzman J, Amaral A. Quantifying the Performance of Individual Players in a Team Activity. PloS One. 2010; 5(6): e10937 [ Link ]

10. Taylor JB, Mellalieu SD, James N, Sheraer D. The influence of match location, qualify of opposition and match status on technical performance in professional association football. Journal of Sports Sciences; 2008. 26(9): 885-895 [Link]

11. Rein R, Memmert D. Big data and tactical analysis in elite soccer: future challenges and opportunities for sports science. SpringerPlus; 2016. 5(1): 1410 [Link]

12. McHale IG, Relton SD. Identifying key players in soccer teams using network analysis and passe difficulty. Eur J Oper Res. 2018; 268 (1): 339 - 347 [ Link ]

13. Schultze $S$, Wellbrock CM. A weighted plus/minus metric for individual soccer player performance. JSA. 2018; 4: 121-131 [ Link ]

14. McHale I, Scarf P, Folker D. On the Development of a Soccer Player Performance Rating System for the English Premier League. Interfaces. 2012; 42(4): 329-420 [ Link]

15. Kishore S, Radhakrishnan T, Karthick M. Impact of skills and drills practice training on postional requirements of defenders midfielders and forwards on kicking ability of high school level football players. Int J Appl Res. 2016; 2(7): 591-594 [ Link ]

16. Baptista I, Johansen D, Seabra A, Pettersen S. Position specific player load during matchplay in a professional football club. PloS One. 2018; 13(5): e0198115 [ Link ]

17. Gioldasis A, Souglis A, Christofilakis O. Techical skills according to playing position of male and female players. IntJSCS. 2017; 5(4): 293-301 [ Link ]

18. Barreira D. Tendências Evolutivas da dinâmica tática em Futebol de alto rendimento: Estudo da fase ofensiva nos Campeonatos da Europa e do Mundo, entre 1982 e 2010. Porto. Tese [Doutorado em Ciências do Desporto]. Universidade do Porto; 2013

19. Hughes M, Caudrelier T, James N, Redwood-Brown A, Donnely I, Kirkbride A, et al. Moneyball and soccer - an analysis of the key performance indicators of elite male soccer players by position. JHSE. 2012; 7(2): 402-412 [ Link ] 
20. Almeida CH, Ferreira AP, Volossovitch A. Effects of Match Location, Match Status and Quality of Opposition on Regaining Possession in UEFA Champions League. J Hum Kinet. 2014; 41: 203-214 [ Link ]

21. Liu H, Yi Q, Giménez JV, Gómez MA, Lago-Peñas C. Performance profiles of football teams in the UEFA Champions League considering situational efficiency. International Journal of Performance Analysis in Sport. 2015; 15(1): 371-390 [ Link ]

22. Liu H, Hopkins WG, Gómez MA. Modelling relationships between match events and match outcome in elite football. European journal of sport science. 2016; 16(5): 516-525 [ Link ]

23. Pereira T, Ribeiro J, Grilo F, Barreira D. The Golden Index: A classification system for player performance in football attacking plays. Proc. Inst. Mech. Eng. P, 2019. [ Link ]

24. Liu H, Gómez M-A, Gonçalves B, Sampaio J. Technical performance and match-to-match variation in elite football teams. J Sports Sci. 2015; 34 (6): 509-518 [ Link ]

25. Clemente F, Martins F, Kalamaras D, Oliveira J, Oliveira P, Mendes R. The social network analysis of Switzerland football team on FIFA World Cup 2014. JPES. 2015; 15 (1): 136-141 [ Link ]

26. Clemente FM, Martins F, Mendes R, Figueiredo A. A systemic overwiew of football game: The principles behind the game. JHSE. 2014; 9(2): 656-667 [ Link ]

27. Grund TU. Network structure and team performance: The case of English Premier League soccer teams. Social Networks. 2012; 34(4): 682-690 [ Link ]

28. Zhu Y. Discovering Key Players and Key Groups in a Soccer Team Using Centrality Measures. Wisconsin. Thesis [Master Degree in Science in Engineering]. University of Wisconsin-Milwaukee; 2015 [ Link ]

29. Barghi A. Analyzing Dynamic Football Passing Network. Ottawa. Thesis [Master Degree in Computor Science]. University of Ottawa; 2015 [ Link ]

30. Peña J, Touchette H. A network theory analysis of football strategies. 2012; arXiv [math.CO] [ Link ]

31. Quina J. Futebol: Referências para a organização do jogo. Bragança, Instituto Politécnico de Bragança, 2001

32. Wiemeyer J. Who should play in which position in soccer? Empirical evidence and unconventional modelling. Int J Perform Anal Sport. 2003; 3(1): 1-18 [ Link ]

33. Cullinane A. Techical comparison of positional roles in professional football. Dissertation [Sport and Physical Education]. University of Wales Institute Cardiff; 2008

34. Marques M. Caracterização e análise do contributo do cruzamento para a finalização. Tese [Licenciatura em Educação Física]. Faculdade de Desporto da Universidade do Porto; 2000

35. Gonçalves B, Coutinho D, Santos S, Lago-Peñas C, Jiménez S, Sampaio J. Exploring Team Passing Networks and Player Movement Dynamics in Youth Association Football. PloS One. 2017; 12(1): e0171156 [ Link ]

36. Jaria I. Metrologia do rendimento desportivo: Análise da interação do jogo de futebol 7 e 11. Tese [Mestrado em Ciências do Desporto e Educação Física]. Faculdade de Desporto da Universidade de Coimbra; 2014 [ Link ]
37. Belli R. Análise da Network e Comportamento colectivo no jogo de futebol. Tese [Mestrado em Treino Desportivo para Crianças e Jovens]. Faculdade de Desporto da Universidade de Coimbra; 2015 [ Link ]

38. Oliveira P, Clemente FM, Martins F. Network measures and digraph theory applied to soccer analysis: Midfielder is the key player in youth teams. JPES. 2016; 16(2): 1023-1028 [ Link ]

39. Gama J, Couceiro M, Dias G, Vaz V. Small-World Networks in professional football: conceptual model and data. Eur. J. Hum. Mov. 2015; 35: 85-113 [ Link ]

40. Ortega JI, Evangelio C, Clemente FM, Martins F, González-Víllora S. Analysis of Physiological, Technical, and Tactical Analysis during a Friendly Football Match of Elite U19. Sports. 2016; 4: 35 [ Link ]

41. Nakanishi R, Murakami K, Naruse T. Dynamic positioning method based on dominant region diagram to realize successful cooperative play. In: Robo cup 2007: Robot Soccer World Cup XI, Vol 5001. Springer. 2008; 488-495 [ Link ]

42. Link D, Link D, Lames M. Validation of electronic performance and tracking systems EPTS under field conditions. PLoS One. 2018; 13(7) [ Link ]

\section{Acknowledgements}

The authors gratefully acknowledge the support of a Spanish government subproject Mixed method approach on performance analysis (in training and competition) in elite and academy sport [PGC2018-098742-B-C33] (Ministerio de Ciencia, Innovación y Universidades, Programa Estatal de Generación de Conocimiento y Fortalecimiento Científico y Tecnológico del Sistema $\mathrm{I}+\mathrm{D}+\mathrm{i}$ ), that is part of the coordinated project New approach of research in physical activity and sport from mixed methods perspective (NARPAS_MM) [SPGC201800X098742CV0].

\section{Corresponding author}

Daniel Barreira

Faculty of Sport, University of Porto, Porto, Portugal

Centre of Research, Training, Innovation and Intervention in Sport (CIFI2D), University of Porto, Portugal

Rua Dr. Plácido Costa, 91, 4200-450, Porto, Portugal

Email: dbarreira@fade.up.pt

Manuscript received on September 16, 2018

Manuscript accepted on November 23, 2018

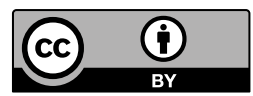

Motriz. The Journal of Physical Education. UNESP. Rio Claro, SP, Brazil - eISSN: 1980-6574 - under a license Creative Commons - Version 4.0 